\title{
Non-immersive virtual reality for Malay and Islamic world museum Melaka: effects from covid-19 pandemic
}

\author{
Khyrina Airin Fariza Abu Samah ${ }^{1 *}$, Nor Intan Shafini Nasaruddin ${ }^{1}$, Mohd Amir Ridhwan Afandi ${ }^{2}$, \\ Nurul Zahirah Abd Rahim ${ }^{3}$, Siti Fatimah Mohd Rum ${ }^{1}$ and Fadhlina Izzah Saman ${ }^{1}$ \\ Senior Lecturer, Faculty of Computer and Mathematical Sciences, Universiti Teknologi MARA Cawangan Melaka \\ Kampus Jasin, Melaka, Malaysia ${ }^{1}$ \\ Scholar, Faculty of Computer and Mathematical Sciences, Universiti Teknologi MARA Cawangan Melaka Kampus \\ Jasin, Melaka, Malaysia ${ }^{2}$ \\ Lecturer, Faculty of Computer and Mathematical Sciences, Universiti Teknologi MARA Cawangan Melaka \\ Kampus Jasin, Melaka, Malaysia ${ }^{3}$
}

Received: 27-September-2020; Revised: 15-January-2021; Accepted: 17-January-2021

(C)2021 Khyrina Airin Fariza Abu Samah et al. This is an open access article distributed under the Creative Commons Attribution (CC BY) License, which permits unrestricted use, distribution, and reproduction in any medium, provided the original work is properly cited.

\begin{abstract} museum where they can only view the artifacts outside the glass container.

\section{Keywords}

Covid-19, Malay and Islamic world museum, Non-immersive, Tourism, Virtual reality.
\end{abstract}

This paper describes the development of Non-Immersive Virtual Reality (NIVR) for the Malay and Islamic World Museum in Malacca in Melaka, Malaysia. The Covid-19 outbreak has caused the most impact in the tourism industry in the first half of 2020, and the situation will not be the same as post-pandemic. Thus, we have developed NIVR to attract the tourist or anyone interested in knowing more in-depth information about the heritage culture available in the museum. The application was designed in the 3D environment platform and focused on the Malay warfare weapons, Keris, Lembing, Tumbuk Lada, and Tekpi. We evaluate the motivation of NIVR, particularly towards user experience on the functionality and system usability score. As a result, the system features are functioning, and we manage to get a usability score of 77.08\%, which rating as a good score. It means that the NIVR for Malay and Islamic World Museum Malacca system has good system usability since the user can learn more about the artifacts compared to the physical

\section{Introduction}

Tourism has become one of the industries that rapidly developed globally, and heritage-based tourism is Malaysia's potential tourism sector. Ramli [1] claimed the attraction towards archaeology, history, and culture had caused it to become a tourism product. Despite there is no prehistoric heritage in Melaka, many museums were being developed with unique architectures from the era of Dutch (Stadhuys) and A Famosa from Portuguese entrance. The museum is defined as non-profit organizations that provide the collection of materials' evidence of peoples, the environments [2] for studies, educations, researchers, and facilitate knowledge creation with various goals, from supporting the specialist and expert to supporting the public [3].

*Author for correspondence

91
Department of Museum Malaysia (1993) categorized the museum as the galleries that protect, preserve, and provide information about the nation's cultural, natural, and historical heritage, and indirectly assist in promoting and building up the tourism industry [4]. Several museums, such as natural history museums, art museums, science museums, children's museums, and war museums. Serving and supporting experts such as researchers are moving towards the public.

However, due to the rapid spread virus of Covid-19 and been declared a pandemic, it has significantly impacted the worldwide and the post-coronavirus facing the new ways in global economic, sociocultural, health-wise, and political effects $[5,6]$. The present crisis affected the tourism industry, and currently, both industry and the government play the roles in the recovery actions. Although the 
Movement Control Order (MCO) loosen the restriction on travel and mobility, people still need to follow standard operating procedures such as social distancing, wearing a facemask, and not allowed big crowds at one time. The public has always been reminded of the hygiene and cleanliness concerns [7], and this scenario implies not only the tourism industry but also the future planning and management $[8,9]$.

Additionally, the ordinary and traditional way of displaying artifacts using texts and pictures caused passive learning activities. Suppose it must be a place where the cultural heritage can be experienced [10], and the displays are possible for the visitors to 'touch' and explore [11]. The artifacts and material collected in the museum collections are risky due to the threat of theft, fire, vandalism, humidity, temperature, and vibration, which caused high maintenance of the artifacts. Other issues and challenges the museum's management faced during MCO were increased sanitization activities and the maximum occupancy regulations. They need to clean and sanitize using a proper protocol and new safety norms due to many interactivities involved during the visit to the museum.

Thus, there is a requirement for virtual conservation of heritage resources technology intervention through the digital storage media and technological museum [12]. $17 \%$ of heritage collections were estimated been digitized, according to [13]. Li et al. [14] agreed on the excellent technology used in the digital museum and claimed that only a few studies study the user experience on technology usage. The dynamic, complex, and empowering learning environments can be a great potential for informal and lifelong learning medium [15]. The future role of museums in local and global cultural contexts are being questioned and radically re-shaped. These items are ready through exhibits, which can be temporary or permanent public viewing through exhibits.

This study motivates using a virtual museum, a digital platform that builds on a museum's features to supplement, augment, or enrich the museum through personalization, engagement, user experience, and rich content. Like in a typical museum, a virtual museum may be built around particular objects, such as an art museum or a natural history museum, or may be made up of multimedia exhibits focused on primary or secondary resources. Besides, a virtual museum may be referred to as a smartphone or World Wide Web offers, such as digital representations of its collections or exhibitions, or digital content such as 3 Dimension (3D) environments, net media, virtual reality, and digital art may be created.

Therefore, this study objective is to implement NonImmersive Virtual Reality (NIVR) using a mobilebased application for the Malay and Islamic World Museum Malacca, Melaka, Malaysia to overcome the mentioned problem. We designed the ideas in a 3D platform and included multimedia elements such as animation, graphics, audio, and text. We are focusing on Malay warfare weapons equipment such as Keris, Lembing, Tumbuk Lada, and Tekpi to give more virtual visual to the audience in the room environment exploration. Then, we evaluate the user experience using the NIVR to ensure we achieve the study's objective.

\section{Related works}

In this section, we explore the VR techniques and explain the reason for choosing the non-immersive. Then, we make a comparison of the existing application similar to the study.

\subsection{Virtual reality}

Today, VR technology is used to advance medicine, engineering, learning, and entertainment. VR is a computer interface that aims to imitate real-world outside the flat display to give an interactive 3D visual experience [16]. Reconstruction of scales and lengths in static 2D pictures is sometimes challenging. Thus, the third dimension tends to deepen artifacts. Digital reality technology produces interactive worlds that will both teach and entertain customers.

Begun during the 1950s, a cinematographer, Morton Heilig, developed a device that can stimulate all detection, inclusive sight, and sound named Sensorama [17]. In 1968, Ivan Sutherland created a Sword of Damocles and the first VR/AR head roof mounted using PC. Later, many advanced VR was developed and introduced, such as Cardboard VR, Google Daydream, Gear VR, Oculus Rift, Vive, Sony PSVR, and Microsoft's HoloLens [18]. When information technology advances, for corporate and commercialization tasks, such as information distribution, marketing, and sales transactions, 3D virtual worlds have emerged [19]. With digital communication channels that are not limited by geographical boundaries, open virtual world markets promote in-world goods and off-world services, offering a platform for creative use of technology to connect consumers with specific brands and 
ultimately influence buying intentions [20]. VR app development has been of major concern these recent times as we have had various people setting up or establishing a VR app development company.

There were three types of VR technology; fullyimmersive, semi-immersive, and non-immersive [21], but we only focus on comparing the most used, fully immersive and non-immersive. Immersive VR is a depiction of a simulated reality that substitutes the real-world experience of users sufficiently persuasively to accept reality and truly embrace the generated environment. VR therapy and VR gaming is an essential element of virtual reality applications called immersiveness. VR is commonly used in education and training because of its ability to promote interactivity and motivation [22]. One of the tools used in immersive VR is Cave Automatic Virtual Environments (CAVE), where the user is in a room with all the walls and the floor screens. Users can wear 3D glasses freely to move around in the projected world. CAVE ecosystems are quite expensive due to the requirement of a special noneasily moved space. The features cause difficulties in training and education and to have a widespread application. For example, Cultural Heritage education mainly used CAVE technology [23]. VR glasses or other forms of Head Mounted Displays (HMD) that are often paired with headphones easily create the visceral feeling of living in a virtual environment. Our five senses should be engaged in full immersion in a virtual environment. Nonetheless, most of today's VR experiences only concentrate on two aspects, which are sight and hearing, and do not tackle all the senses. Specifically, as claimed by [24], sight is considered the most important sense, and it is connected strongly with purpose.

Non-immersive VR is a type of technology that provides computer-generated content to users with no sense of immersion in the virtual environment. The key feature of a non-immersive VR device is that users can retain awareness of the physical world while being mindful of what's going on around them, such as sounds, visuals and haptics. Non-immersive VR systems rely on computer or video game console, monitor, and input devices such as keyboards, mice, and controllers. As supported by [25], non-immersive VR makes it possible to communicate with the world using a cursor or joystick, whereas immersive VR uses instruments linked to the human body to execute the same movement activity.

In the 3D content distribution system, the key distinction between immersive and non-immersive VR. Completely interactive VR is a practical simulation platform that helps users to communicate with a simulated 3D world utilizing special haptic interfaces. Unlike non-immersive VRs based on traditional displays, completely immersive VRs include a computer-generated experience through head-mounted displays (HMDs) that separate users from the real world and become unaware of physical objects and sounds. However, the pandemic issue of Covid-19 prevents this project from being implemented in immersive virtual reality to use devices to control the environment.

\subsection{Review of similar existing application}

Many existing applications are available, and this section only focuses on two similar applications to the study. The first application is the 'VR Museum', which gives the user the experience to be immersed in the VR museum, followed by 3D scans of Aztec and Mayan statues as well as gazing into a painting to teleport into the scene. It also transforms the museum experience and redefines how art is created and deployed in the future. The second application, Jurassic VR-Google Cardboard, allows users to experience the ultimate dinosaur ride and free roam the open environment to learn more about dinosaurs back in time. Explore the island's Jurassic shores and dense jungle and learn about this chapter in history. Safely observe the deadly creatures as they prowl their natural habitat.

The comparison is made according to each application's features and elements, as illustrated in Table 1. Based on the comparison, the implementation ideas are similar to the Jurassic VRGoogle Cardboard and meet the plan of using nonimmersive using mobile applications to get attractive usage between the user and the application. 
Khyrina Airin Fariza Abu Samah et al.

Table 1 Comparison with existing application

\begin{tabular}{|c|c|c|c|}
\hline $\begin{array}{l}\text { Application/ } \\
\text { Characteristic }\end{array}$ & VR Museum & Jurassic VR-Google Cardboard & $\begin{array}{l}\text { Malay and Islamic World } \\
\text { Museum VR }\end{array}$ \\
\hline Content & $\begin{array}{l}\text { Transform the museum } \\
\text { experience and redefine } \\
\text { how art is created and } \\
\text { deployed in future }\end{array}$ & $\begin{array}{l}\text { Roam the open environment and } \\
\text { poke round the beautiful cedar } \\
\text { evergreen trees to see huge } \\
\text { dinosaurs become alive. User can } \\
\text { go to any point and see the sites } \\
\text { and dinosaurs in VR }\end{array}$ & $\begin{array}{l}\text { Allow user to experience the } \\
\text { immersive environment in the } \\
\text { museum and redefined how the } \\
\text { history of Malay and Islam are } \\
\text { created such as warfare } \\
\text { equipment }\end{array}$ \\
\hline Technology & VR in Mobile Application & VR in Mobile Application & VR in Mobile Application \\
\hline Platform & IOS & Android and IOS & Android \\
\hline Dimension & $3 \mathrm{D}$ & $3 \mathrm{D}$ & $3 \mathrm{D}$ \\
\hline Multimedia element & Text, image and sound & Text, image, sound and animation & $\begin{array}{l}\text { Text, image, sound and } \\
\text { animation }\end{array}$ \\
\hline Interface & $\begin{array}{l}\text { Lack of interactivity and } \\
\text { animation as it appears } \\
\text { boring to the user }\end{array}$ & $\begin{array}{l}\text { Easy to use and interact. The } \\
\text { graphics are nice, and the } \\
\text { animation is quite attractive }\end{array}$ & $\begin{array}{l}\text { Interesting and attractive to use. } \\
\text { More interactivity between the } \\
\text { user and the application }\end{array}$ \\
\hline
\end{tabular}

\section{Research method}

This section provides an overview of the project methodology used to achieve the goal of the study. The selected model adapted is the Analysis, Design, Development, Implementation, and Evaluation (ADDIE) Model, which consists of five phases: 1) analysis, 2) design, 3) development, 4) implementation and 5) evaluation. ADDIE is considered as dynamic and flexible techniques in developing effective training and supporting tools for performance. ADDIE was selected because it is commonly used in the instructional design field [26] to create an efficient and effective teaching design. Besides, the spin-offs or variations of ADDIE can receive consistent or constructive guidance as teaching materials and are considered an effort to save time and resources.

\subsection{Analysis}

In this phase, we analyze the problem, identify the objectives, and the study's scope. Then, we classify the outcome based on the objective and use it as the input for the design process. Specific software and hardware are identified for development purposes. Three main software selected, firstly Autodesk 3Ds Max and Blender, a professional 3D computer graphics program used to design and create a 3D model character such as visitor (first person), museum, and warfare equipment 'keris', 'tumbuk lada', 'tekpi', and 'lembing'. Second, software Unity $3 \mathrm{D}$, a cross-platform game engine that is used to create a virtual environment. Third, software Adobe Audition, a digital audio editor used to edit and create the application's sound. Fourth, Adobe Premiere Pro was used to create, edit, and trim videos for the warfare equipment. Then all the videos will be exported into Unity 3D. Fifth, Visual Studio is used to edit and debug \# files, for example, to move the player, machines, and the button's function.

Two hardware specification parts: 1) design and the development of the application, and 2) the user is running or executing the application. For the development, the specification such as CPU: Intel@ Core $^{\mathrm{TM}}$ i5-7200U CPU @ 2.50GHz, GPU: Nvidia GeForce 940 MX, OS: Windows 10, RAM: 8GB, and sound card: Aspire E 15. The only difference is the GPU, RAM, and CPU must have the same specifications or above for the user's specification.

\subsection{Design}

Our strategy starts with developing the instruction flow on how to run the system using the flowchart in the design phase, as in Figure 1. It functions as the guideline for this study where the application started with the main page displayed, and the user can select the enter button to start the non-immersive VR. Users can play the virtual environment application and manipulate the artifacts followed by the specific video.

\subsection{Development}

In the third phase, we start developing a VR mobile application of Malay and Islamic World museums. The development starts with the homepage creation using Unity 3D in Figure 2, followed by creating the museum model using Blender software in Figure 3, and Figure 4 shows how the warfare artifacts are created in Blender and exported into Unity 3D workspace. 


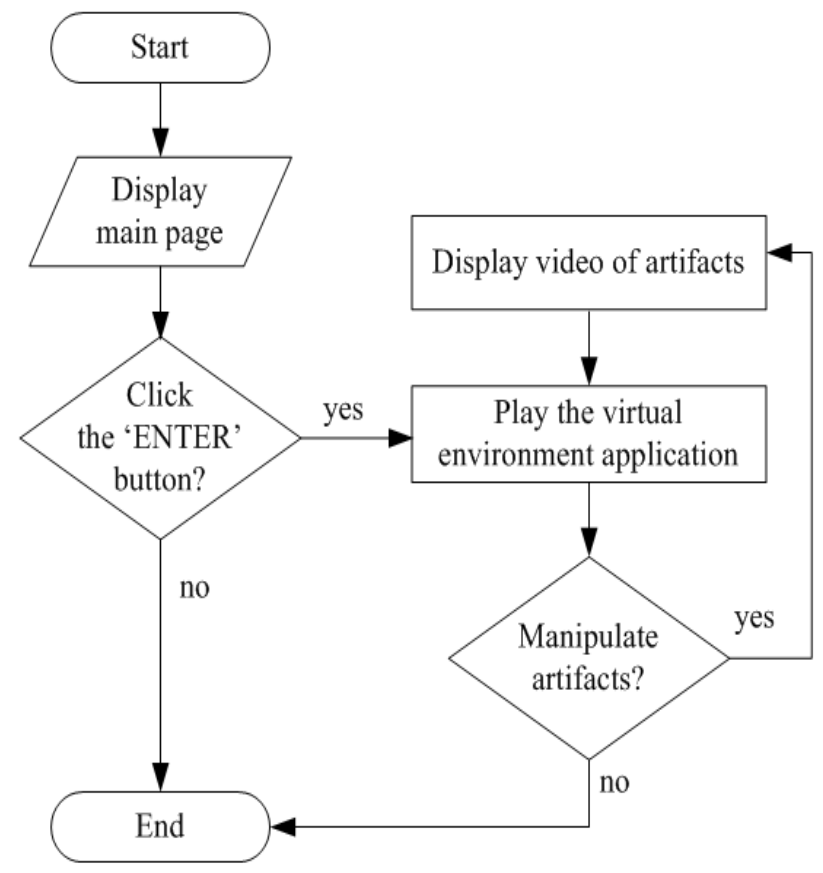

Figure 1 Process flow flowchart on how to run the application of NIVR for Malay and Islamic world museum Malacca

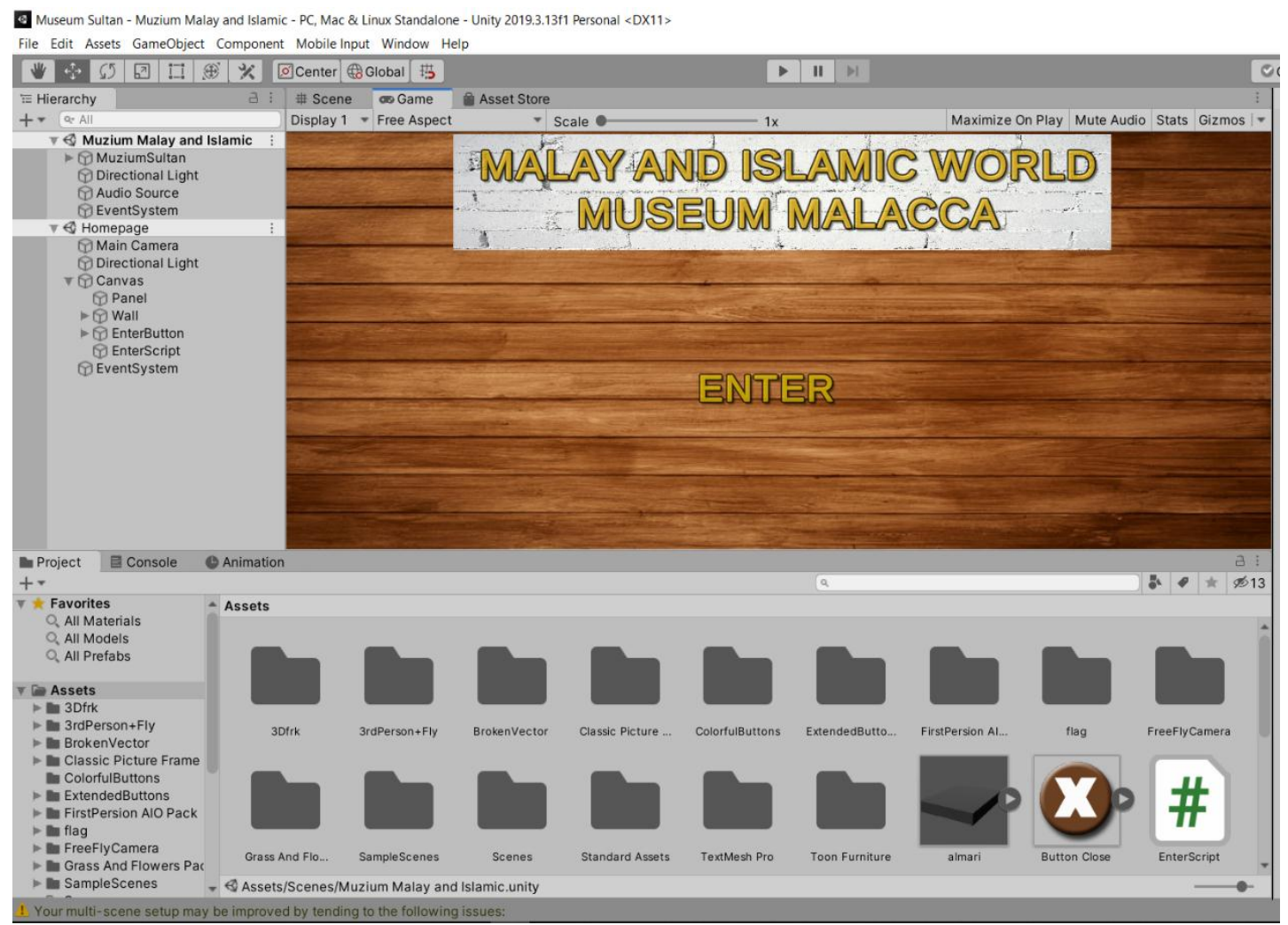

Figure 2 Main menu creation using unity 3D 
Khyrina Airin Fariza Abu Samah et al.

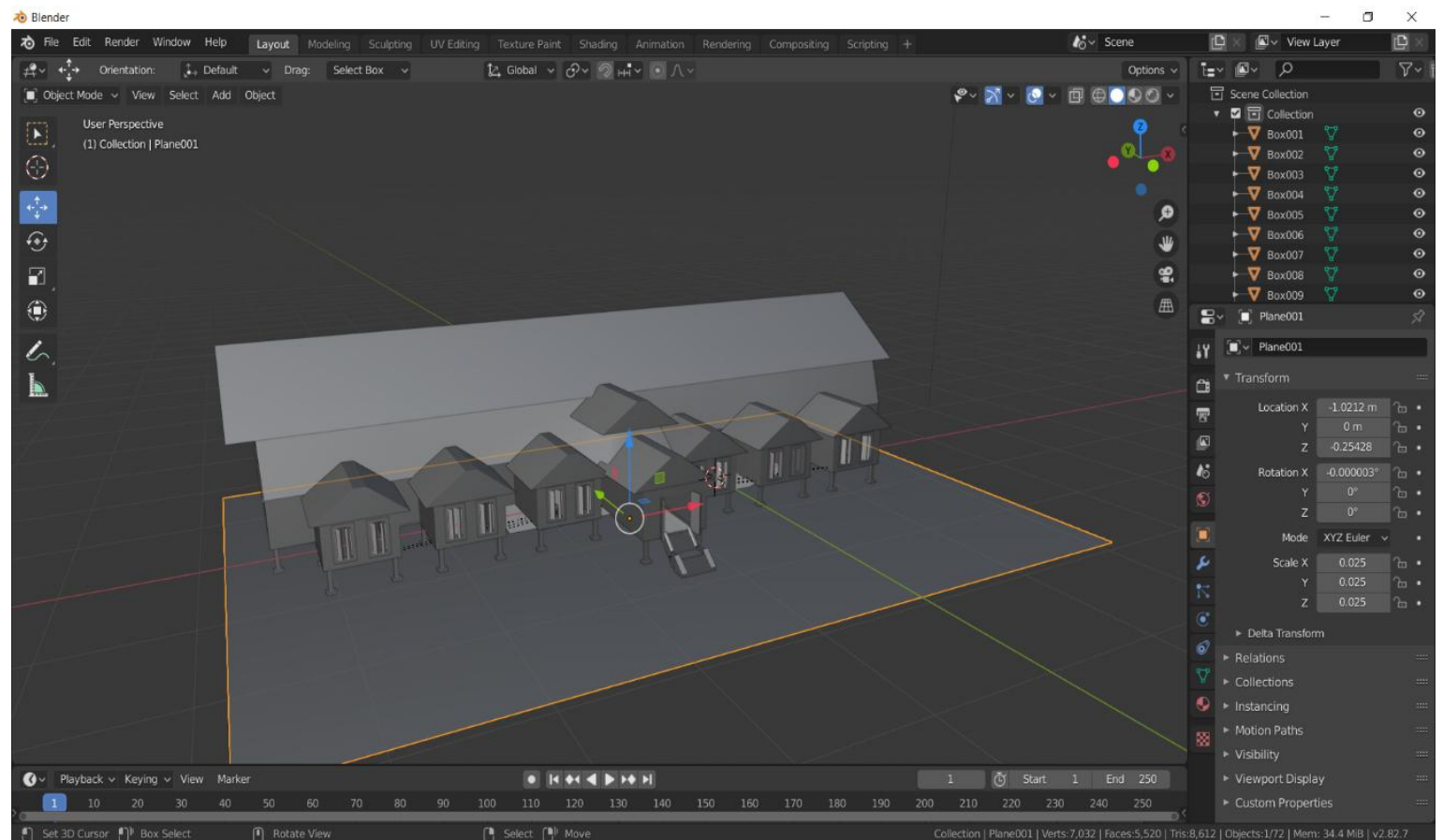

Figure 3 Creation of museum model using blender

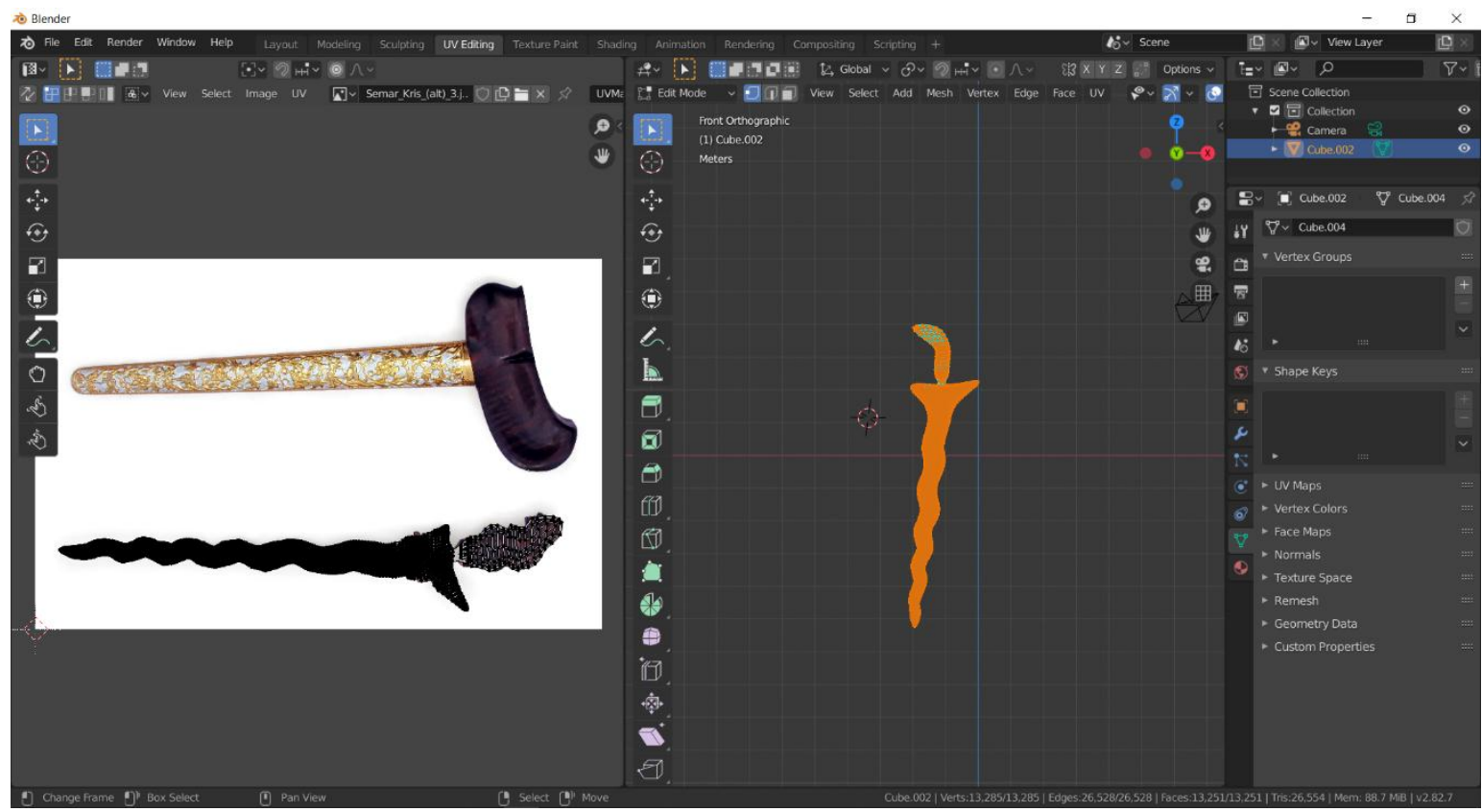

Figure 4 Creation of warfare artifacts using blender

\subsection{Implementation}

The implementation phase refers to the actual delivery of the VR mobile application to the target user. In this phase, the application is revised, modified, and edited to ensure the objective is achievable. This effectiveness of the application result is evaluated time by time.

\subsection{Evaluation}

The last phase in this ADDIE Model is the evaluation phase. We evaluate two types of testing to ensure the effectiveness of the system: functionality and usability. The functionality test involves all the buttons available in the system, and the VR usability tested using the System Usability Scale (SUS) model. 
The SUS is a widely used standardized questionnaire for the assessment of perceived usability [27]. We set to collect the minimum number of 30 respondents' feedback due to MCO during the pandemic, and they were selected randomly. Each of them was given 10 minutes to play the application and answer the SUS directly after playing the application. The questionnaire using Google form with Likert-scale one to five represents the 'Strongly Disagree', followed by the rest 'Disagree', 'Neutral', 'Agree', and 'Strongly Agree'.

Due to the alternating sound of the components and the early decision to manipulate the score from 0 to 100 , the traditional approach to measurement is quite tricky. This section offers a summary, before reviewing SUS studies, of psychometric approaches for assessment of the accuracy of structured questionnaires, with the focus on validity (the calculation of what a questionnaire measures), reliability (measuring consistency), and responsiveness (the effect of independent variables on measures).

\section{Result and discussion}

This section presented and discussed the result gained from the highlighted idea in this paper: implementing a mobile-based application using nonimmersive VR for Malay and Islamic World museum.

\subsection{Functionality test}

The functionality testing is done by checking the available button in the application and following the museum's exploration. Figure 5 shows a snapshot of the main menu interface. After we run the application, we can hear the application background music, the button 'Enter', and the museum's text. When the button is selected, the user can explore the museum model for playing the virtual environment in Figure 6. At this stage, we can see the museum's name, background music, and animation for the museum model. Finally, the user can explore the warfare artifacts scene in Figure 7. The text appears to show the name of the artifacts, background music, animation, and video for each artifact.

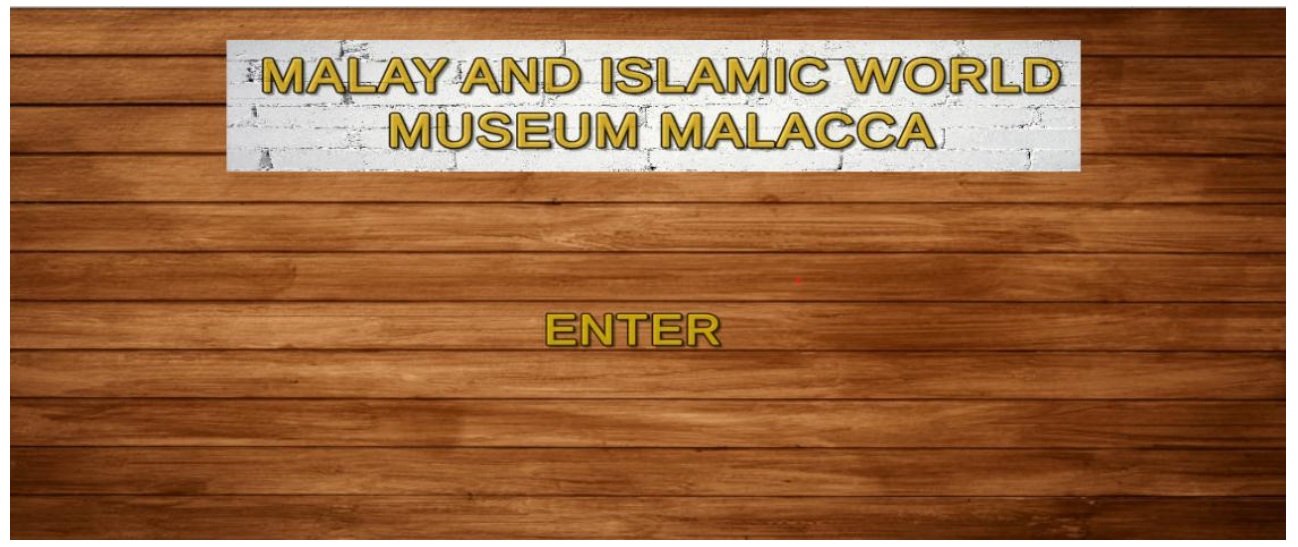

Figure 5 Interface of main menu

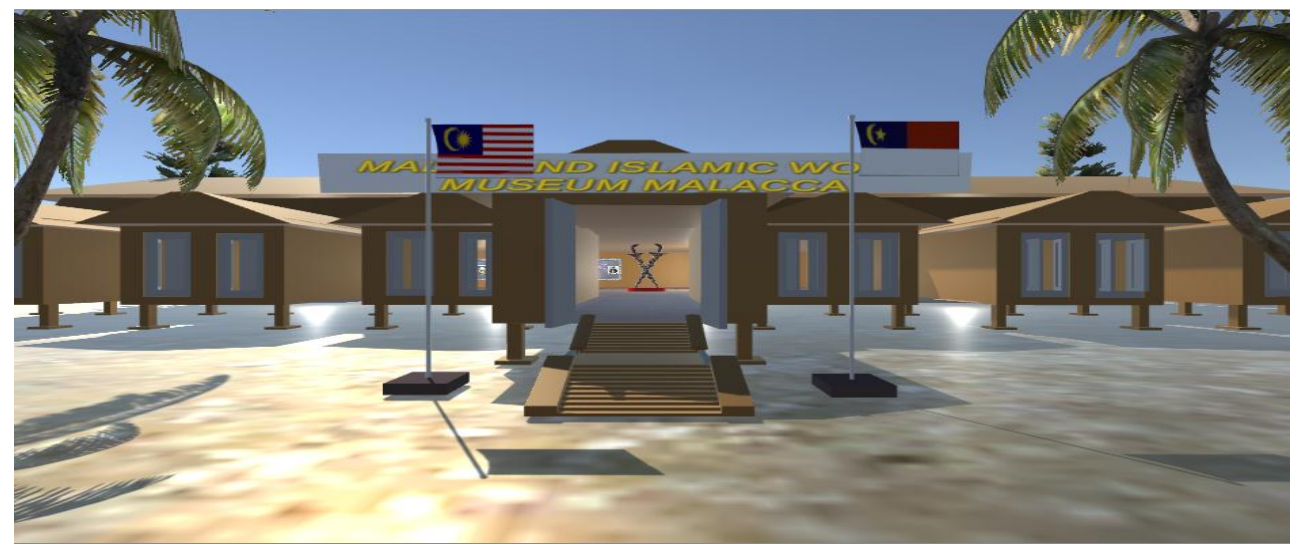

Figure 6 Museum model for playing virtual environment 


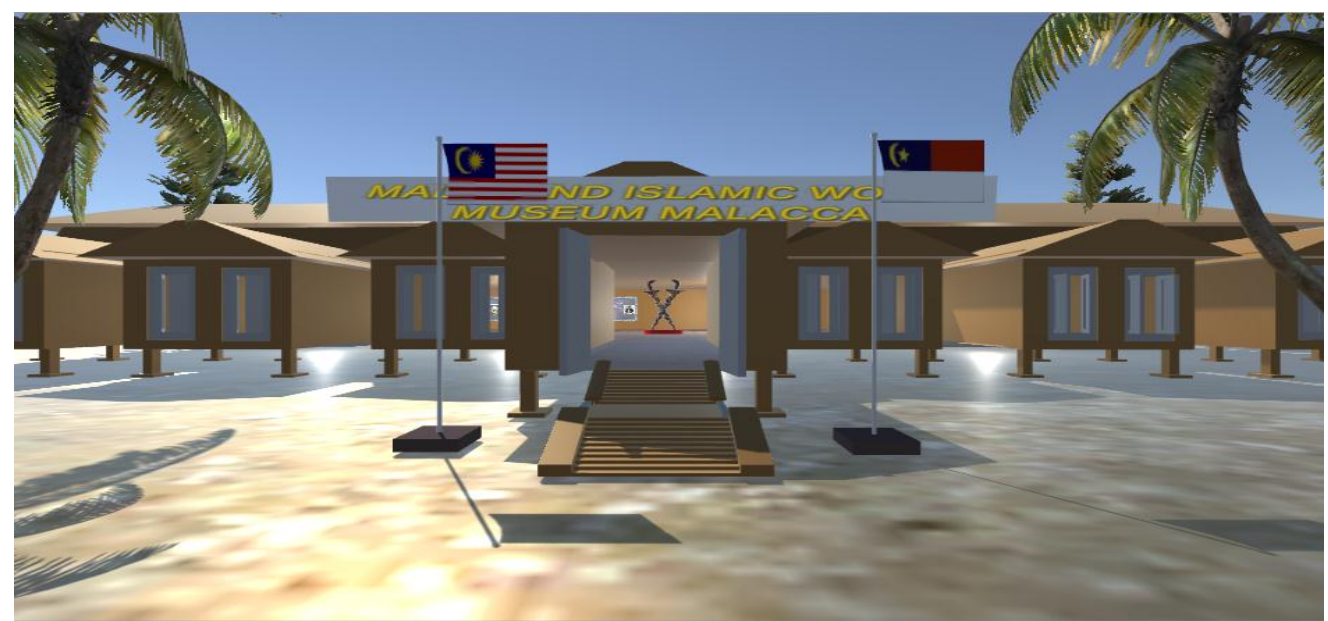

Figure 7 Warfare artifacts scene

\subsection{Usability test}

We summarize the result score as in Figure 8 for each question. To calculate the SUS result, we need to minus 1 from the scale position for the odd question number. Then, for the even question number, we minus 5 with the scale position. We get the average score from 30 respondents over 40 and multiplied it by 2.5 to get SUS's overall scores. The SUS score result interprets either the system's performance is excellent or poor.

A total score of 2312.5 was obtained from the respondents, and we manage to get $77.08 \%$, an average score of SUS. The histogram in Figure 9 shows the highest SUS scores of $75 \%$ to $80 \%$ with 7 respondents. The lowest range is $50 \%$ to $60 \%$ score with 1 respondent, and the highest range is $95 \%$ to $100 \%$ score with 1 respondent.

The SUS general guideline stated that the SUS scores range between 68 to 80.3 is 'B grade' with adjective rating 'Good'. Therefore, since this study managed to get an average SUS of $77.08 \%$, which is reaches and exceeded more than $68 \%$, it means that the NIVR for Malay and Islamic World Museum Malacca system has good system usability since the user can learn more about the artifacts compared to the physical museum where they can only view the artifacts outside the glass container.

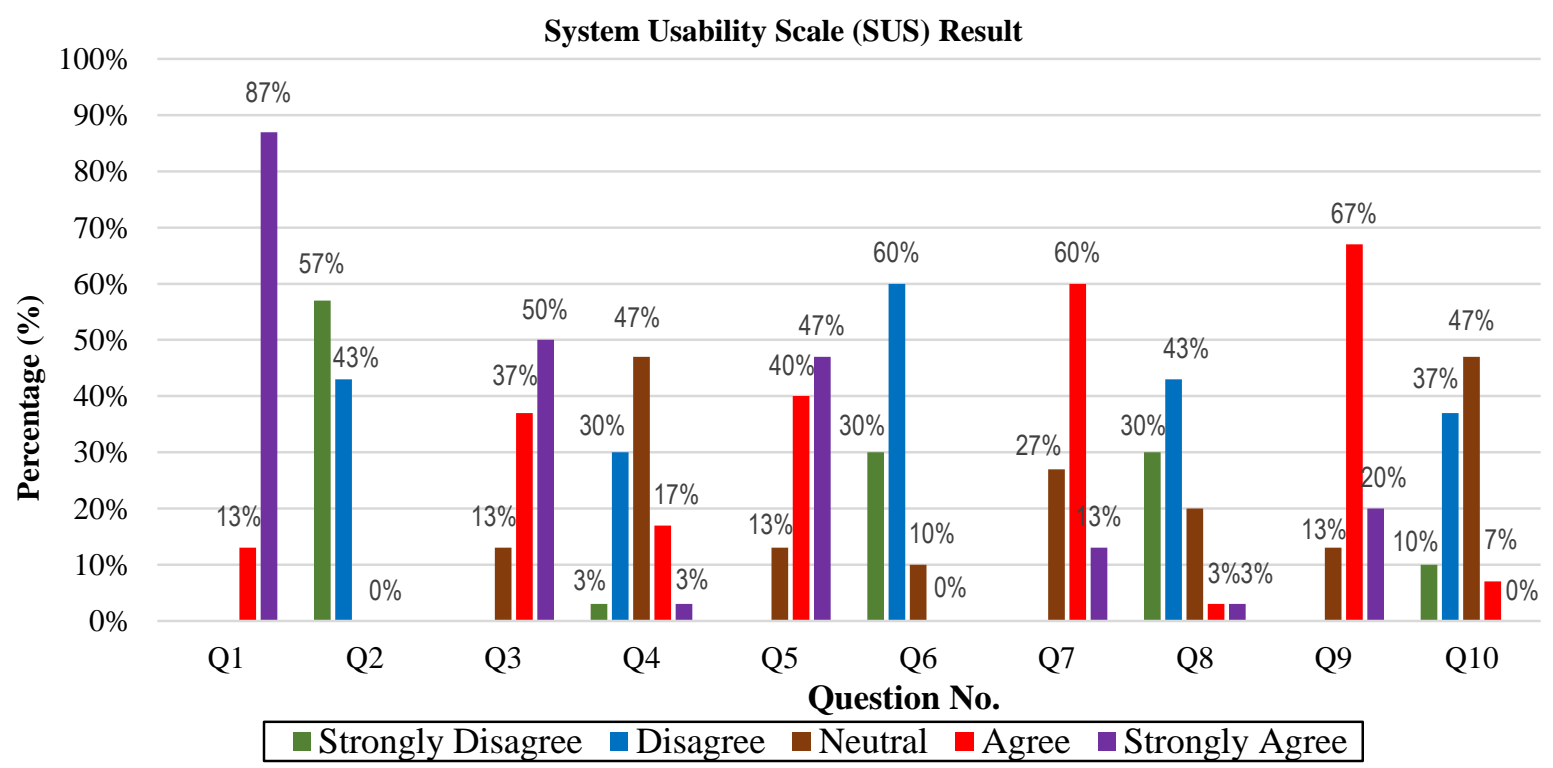

Figure 8 SUS result by question 


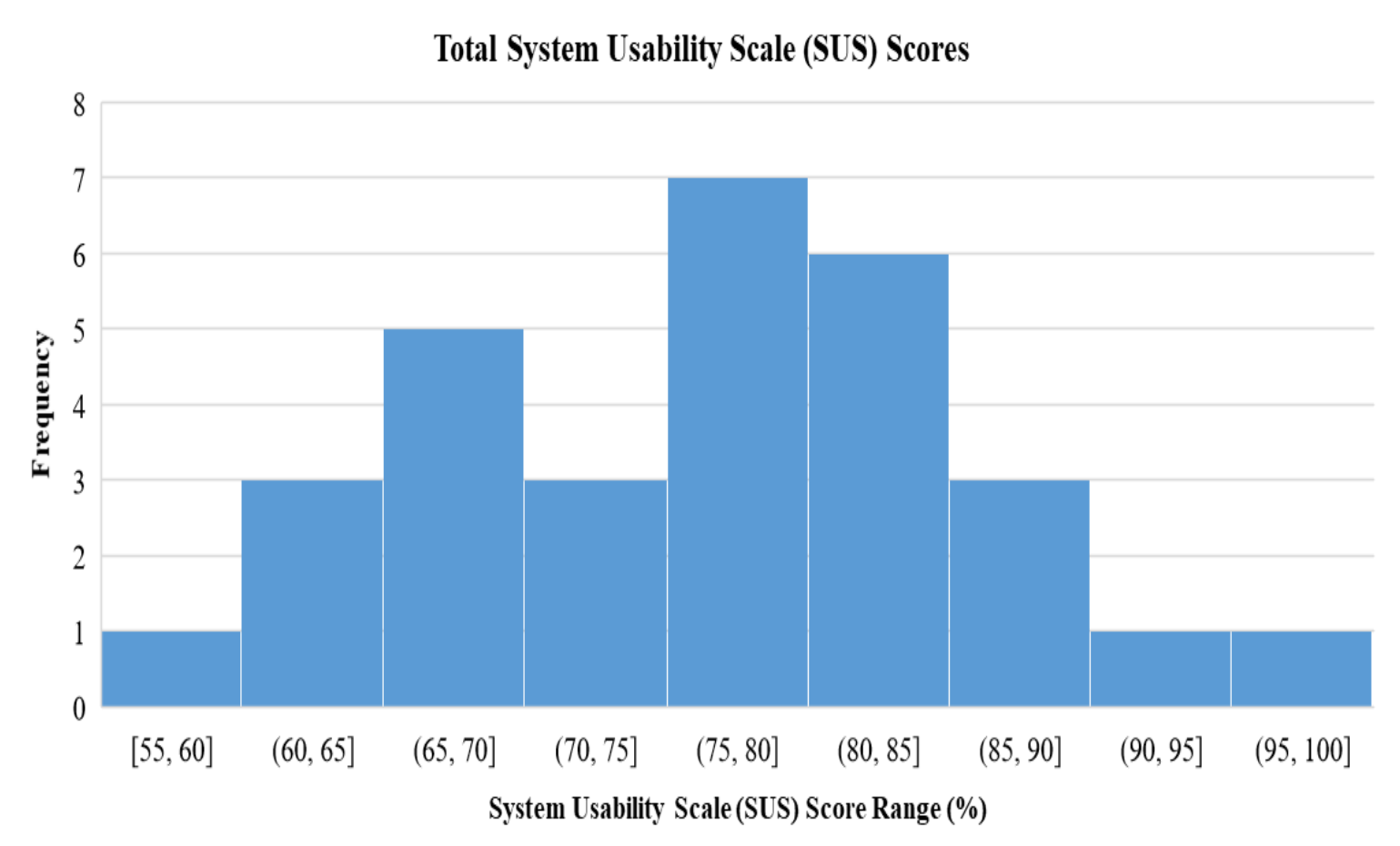

Figure 9 Histogram of SUS scores

\section{Conclusion}

This paper presents the main aimed to overcome the tourism impacts during the MCO due to the Covid-19 pandemic. The tourist or anyone interested to view the artifacts able to view the environment scene the same as a real physical museum. The case study selected was Malay and Islamic World Museum Malacca, and it proved the application is accepted through the functionality and usability test. NIVR for Malay and Islamic World Museum Malacca is considered a good and accepted system. For future research, it can be improved by manipulating the object and adding more animation to play and interact more with the object.

\section{Acknowledgment}

The research was sponsored by Universiti Teknologi MARA Cawangan Melaka under the TEJA Grant 2020 (GSAT2020-18).

\section{Conflicts of interest}

The authors have no conflicts of interest to declare.

\section{References}

[1] Ramli Z. Archaeology, culture, and history: concept and potential as a product of heritage tourism in Malaysia and Indonesia. In selected topics on archaeology, history and culture in the malay world 2018 (pp. 1-18). Springer, Singapore.
[2] Ambrose T, Paine C. Museum basics. Routledge; 2012.

[3] Bakhshi H, Throsby CD. Culture of innovation: an economic analysis of innovation in arts and cultural organisations. NESTA; 2010.

[4] Hashim AF, Taib MZ, Alias A. The integration of interactive display method and heritage exhibition at museum. Procedia-Social and Behavioral Sciences. 2014; 153:308-16.

[5] Sharfuddin S. The world after Covid-19. The Round Table. 2020; 109(3):247-57.

[6] Assaf A, Scuderi R. COVID-19 and the recovery of the tourism industry. 2020; 26(5): 731-3.

[7] Wen J, Wang W, Kozak M, Liu X, Hou H. Many brains are better than one: the importance of interdisciplinary studies on COVID-19 in and beyond tourism. Tourism Recreation Research. 2020:1-4.

[8] Romagosa F. The COVID-19 crisis: opportunities for sustainable and proximity tourism. Tourism Geographies. 2020: 22(3): 690-4.

[9] Samah KA, Arip MA, Deraman NA, Buja AG, Jono MN. Soil moisture monitoring for plant irrigation: a botanic tourism sustainability during Covid-19 pandemic. International Journal of Emerging Trends in Engineering Research. 2020; 8(1.1):82-9.

[10] Cloonan MV. Preserving our heritage: perspectives from antiquity to the digital age. 2015.

[11] Roberts J, Lyons L, Cafaro F, Eydt R. Interpreting data from within: supporting humandata interaction in museum exhibits through perspective taking. In proceedings of the conference on interaction design and children 2014 (pp. 7-16). 
[12] Bello RW, Mohamed AS. Impact of technology on traditional museum collection storage and management. International Journal of Computer Science and Mobile Computing. 2018; 7(11):46-51.

[13] Stroeker N, Vogels R. Survey report on digitisation in European cultural heritage institutions 2014. ENUMERATE - Survey Report on Digitisation in European Cultural Heritage Institutions 2014.

[14] Li YC, Liew AW, Su WP. The digital museum: challenges and solution. In international conference on information science and digital content technology 2012; 646-9. IEEE.

[15] Kristinsdóttir A. Toward sustainable museum education practices: confronting challenges and uncertainties. Museum Management and Curatorship. 2017; 32(5):424-39.

[16] Guttentag DA. Virtual reality: applications and implications for tourism. Tourism Management. 2010; 31(5):637-51.

[17] https://www.vrs.org.uk/virtual-reality/history.html. Accessed 04 August 2020

[18] https://hub.packtpub.com/top-7-modern-virtualreality-hardware-systems/. Accessed 05 August 2020.

[19] Barnes SJ. Understanding use continuance in virtual worlds: empirical test of a research model. Information \& Management. 2011; 48(8):313-9.

[20] Animesh A, Pinsonneault A, Yang SB, Oh W. An odyssey into virtual worlds: exploring the impacts of technological and spatial environments on intention to purchase virtual products. Mis Quarterly. 2011; 35(3):789-810.

[21] Gilson S, Glennerster A. High fidelity immersive virtual reality. Virtual Reality-Human Computer Interaction. 2012. IntechOpen.

[22] Ott M, Tavella M. A contribution to the understanding of what makes young students genuinely engaged in computer-based learning tasks. Procedia-Social and Behavioral Sciences. 2009; 1(1):184-8.

[23] Ott M, Pozzi F. ICT and cultural heritage education: which added value? In World summit on knowledge society 2008 (pp. 131-8). Springer, Berlin, Heidelberg.

[24] Classen C. Foundations for an anthropology of the senses. International Social Science Journal. 1997; 49(153):401-12.

[25] Piron L, Turolla A, Agostini M, Zucconi CS, Ventura $\mathrm{L}$, Tonin $\mathrm{P}$, et al. Motor learning principles for rehabilitation: a pilot randomized controlled study in poststroke patients. Neurorehabilitation and Neural Repair. 2010; 24(6):501-8.

[26] Aldoobie N. ADDIE model. American International Journal of Contemporary Research. 2015; 5(6):68-72.
[27] Mol M, Van Schaik A, Dozeman E, Ruwaard J, Vis C, Ebert DD, et al. Dimensionality of the system usability scale among professionals using internet-based interventions for depression: a confirmatory factor analysis. BMC Psychiatry. 2020; 20:1-10.

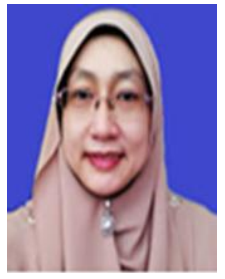

Khyrina Airin Fariza Abu Samah is a senior lecturer at Faculty of Computer and Mathematical Sciences in Universiti Teknologi MARA (UiTM), Melaka Jasin Campus. She has 13 years of working experience in the Information Technology field in the semiconductor industry before joining UiTM. She has Diploma, Bachelor's Degree and Master's Degree in Computer Science and $\mathrm{PhD}$ in Information Technology. Her research interest in Artificial Intelligent, Operational Research, Algorithm Analysis, Clustering and Optimization, Evacuation Algorithm, Internet of Things (IoT) and Sentiment Analysis.

Email: khyrina783@uitm.edu.my

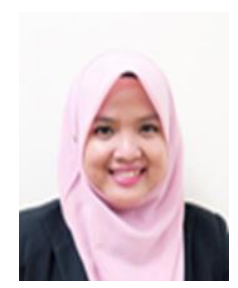

Nor Intan Shafini Nasaruddin is a senior lecturer at the Faculty of Computer and Mathematical Sciences in Universiti Teknologi MARA (UiTM), Melaka Jasin Campus. She completed her $\mathrm{MSc}$ in Computer Science and BSc in Information Technology. Her research interests are Educational Technology, Multimedia Development and Human-Computer Interaction.

Email: intanshafini@tmsk.uitm.edu.my

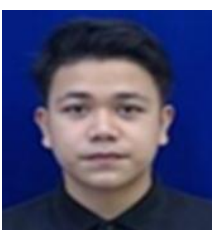

Mohd Amir Ridhwan Afandi is a Bachelor student in Computer Science Multimedia Computing that currently undergoing his internship programme. His research interests are Graphic Design, Games and Animation.

Email: amirreez123@gmail.com

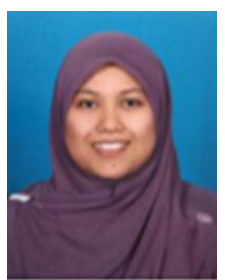

Nurul Zahirah Abd Rahim is a lecturer at Faculty of Computer and Mathematical Sciences, Universiti Teknologi MARA (UiTM), Melaka Jasin Campus. She received her Bachelor's degree in Mathematics from Universiti Teknologi MARA, Malaysia. She completed her Master's degree majoring in Mathematics at Universiti Kebangsaan Malaysia (UKM). Her areas of interest are Dynamical System and Chaotic Behavior.

Email: nurul1867@uitm.edu.my 


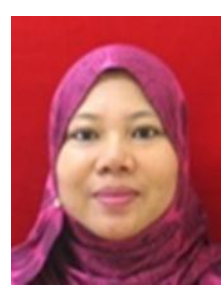

Siti Fatimah Mohd Rum is currently a senior lecturer at the Faculty of Computer and Mathematical Sciences, Universiti Teknologi MARA (UiTM), Melaka Jasin Campus. She holds a Masters of Science in Information Technology (MSc.IT) degree from Universiti Teknologi MARA Malaysia, obtained her Bachelor of Science (BSc.) degree in Computer Science from Victoria University of Technology (VUT), Australia. She was an IT Executive in a private company that specializes in digital printing and bulkmailing service for 6 years and join UiTM as a lecturer in 2007. Her vast experiences during her time as an IT Executive allows her to share the real-life working environment with the undergraduate students.

Email: fatimah418@uitm.edu.my

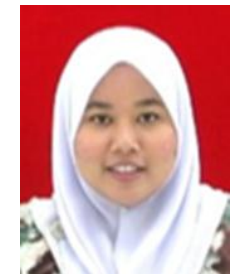

Fadhlina Izzah Saman is a Senior Lecturer at the Faculty of Computer and Mathematical Sciences in Universiti Teknologi MARA (UiTM) Cawangan Melaka Kampus Jasin. She obtained her BSc and MSc in Computer Science from Universiti Teknologi Malaysia (UTM) in 2005 and 2007, respectively. Her research interests are in Game Based Learning (GBL), AI and Machine Learning.

Email: fadhlina218@uitm.edu.my 